\title{
Preliminary report on the Sanyi-Puli seismic zone conductivity anomaly and its correlation with velocity structure and seismicity in the Northwestern Taiwan
}

\author{
Chien-chih Chen ${ }^{1}$ and Chow-son Chen $^{2}$ \\ ${ }^{1}$ Institute of Earth Sciences, Academia Sinica, Nankang, Taipei, Taiwan \\ ${ }^{2}$ Institute of Geophysics, National Central University, Chungli, Taiwan
}

(Received November 5, 1999; Revised March 24, 2000; Accepted March 25, 2000)

\begin{abstract}
As part of seismotectonic investigations in Northwestern Taiwan, eight magnetotelluric (MT) soundings were conducted across the Sanyi-Puli seismic zone, a distinct NW-SE trending linear seismic zone in the fold-thrust belt of Northwestern Taiwan. A preliminary one-dimensional resistivity model according to the determinant MT response was computed, and the resistivity model includes a high-conductivity anomaly beneath this seismic zone. This conductivity anomaly raises the possibility of metamorphic dehydration triggering the seismic events in the seismic zone. The correlation between the conductivity anomaly and active seismicity in this area is tentatively discussed in this study.
\end{abstract}

\section{Introduction}

The Island of Taiwan is located in the active boundary between the Philippine Sea plate and the Eurasian plate (Fig. 1). The relative plate velocity between the Philippine Sea plate and Eurasian plate is $\sim 71 \mathrm{~km}$ per million year and approximately in the direction $\mathrm{N} 50^{\circ} \mathrm{W}$ (Seno et al., 1993). The rapid arc-continental collision is responsible for the rugged topography, the complex geological setting, and the active seismicity in Taiwan.

The Sanyi-Puli seismic zone with a length of $\sim 100 \mathrm{~km}$ and a width of 15-20 km is a distinct NW-SE trending linear seismic zone in the fold-thrust belt of Northwestern Taiwan (Fig. 1). More than 10,000 earthquakes with $M_{L}<5.3$ occurred at the depth above $\sim 40 \mathrm{~km}$ within this area between 1991 and 1997, and these seismic events were recorded by the Taiwan Central Weather Bureau seismic network (CWBSN). There were also five $M_{L} \geq 6.0$ earthquakes occurring along the strike of this seismic zone since 1900, say, the 1935 Hsinchu-Taichung earthquake with $M_{L}=7.1$.

Deffontaines et al. (1994) identified a left-lateral Sanyi transfer fault zone, according to a multisource geomorphic study, in the Western Foothills in Taiwan, whereas Hsu et al. (1996) also found the left-lateral Puli fault within this seismic zone (Fig. 1). According to the study of focal mechanisms, both Lin and Roecker (1993) and Rau et al. (1998) suggested that a deep normal faulting contributes to the seismicity in this area, while they had different views on the causes of the normal faulting.

Seismogenic faulting is commonly associated with zones of fluid overpressure (Gudmundsson, 1999). At the midcrustal depths, near the brittle-ductile transition, metamorphic dehydration may supply a major source of fluids. To

Copy right (C) The Society of Geomagnetism and Earth, Planetary and Space Sciences (SGEPSS); The Seismological Society of Japan; The Volcanological Society of Japan; The Geodetic Society of Japan; The Japanese Society for Planetary Sciences. address the mechanism for earthquakes nucleating at the midcrustal depths, Ague et al. (1998) proposed recently a new earthquake nucleation model, based on a kinetic description of the dehydration process, for repeatedly generating elevated pore fluid pressure $(P f)$ in metamorphic systems.

The MT measurements across the Sanyi-Puli seismic zone, as a part of the integrated project of seismotectonic investigations in Northwestern Taiwan, had been completed during the last two years. Preliminary interpretation is presented in this letter. The frequent seismic events in this region and the relevant geophysical investigations provide us an exceptional opportunity to examine the appropriateness of the earthquake nucleation model in terms of metamorphic dehydration and, consequently, to discuss the possible causes of Sanyi-Puli seismic zone.

\section{2. $S$-wave Velocity Structure}

To synthesize the seismograms of six earthquakes recorded by the Taiwan strong motion network within the Sanyi-Puli seismic zone, Lee (1999), based on a generalized ray theory and finite difference method, presented several $S$-wave velocity profiles across this Sanyi-Puli seismic zone. Profile EE', the one nearest our MT measurements, accompanying seismic events nearby this profile is chosen to display in Fig. 2. The raypath distribution is good and the resolution for each reflection is high enough to trace the variations along this profile (Lee, 1999).

Above Moho, as shown in Fig. 2, there are four layers, corresponding to the various $S$-wave velocities of 2.6, 3.1, 3.5, and $4.0 \mathrm{~km} / \mathrm{s}$ and the various densities of $2.0,2.3,2.6$, and $2.9 \mathrm{~g} / \mathrm{cm}^{3}$, revealed in this profile. While the first two shallower layers show almost no variations in thickness across the Sanyi-Puli seismic zone, both the Conrad and Moho discontinuities display sharp changes in depth. The Conrad discontinuity averages $18 \mathrm{~km}$ in depth beneath the Western Foothills, transferring to $22 \mathrm{~km}$ beneath the Hsuehshan 


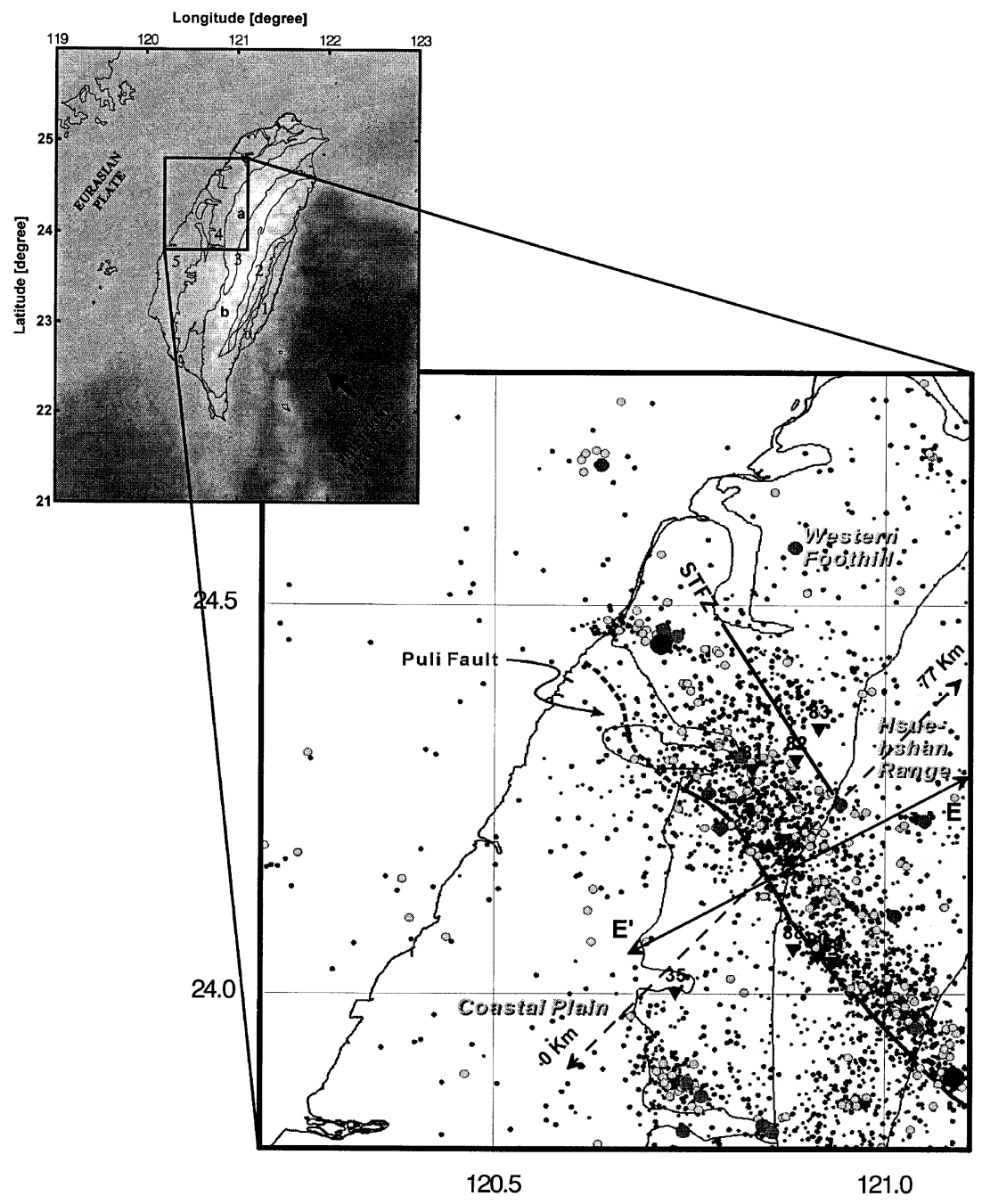

Fig. 1. Map of the Sanyi-Puli seismic zone showing locations of magnetotelluric soundings and 2D velocity profile, EE', in this study. The dashed line with end-arrows extended $77 \mathrm{~km}$ is the MT pseudo-profile; all the MT soundings are projected onto this profile. Epicenters of earthquakes (circles with various sizes and gray colors denote various magnitudes) occurred between 1991 and 1997 display a distinct northwest-southeast-trending linearity. Puli fault is situated in this linear seismic zone. Sanyi transfer fault zone (STFZ) is also identified in this study area. On the left-upper inset map of the tectonic and geological structure of Taiwan are: (1) Coastal Range; (2) eastern Central Range; (3) western Central Range: (a) Hsuehshan Range and (b) Bockbone Range; (4) Western Foothill; (5) Coastal Plain. Thick arrow indicates the relative direction of plate motion.

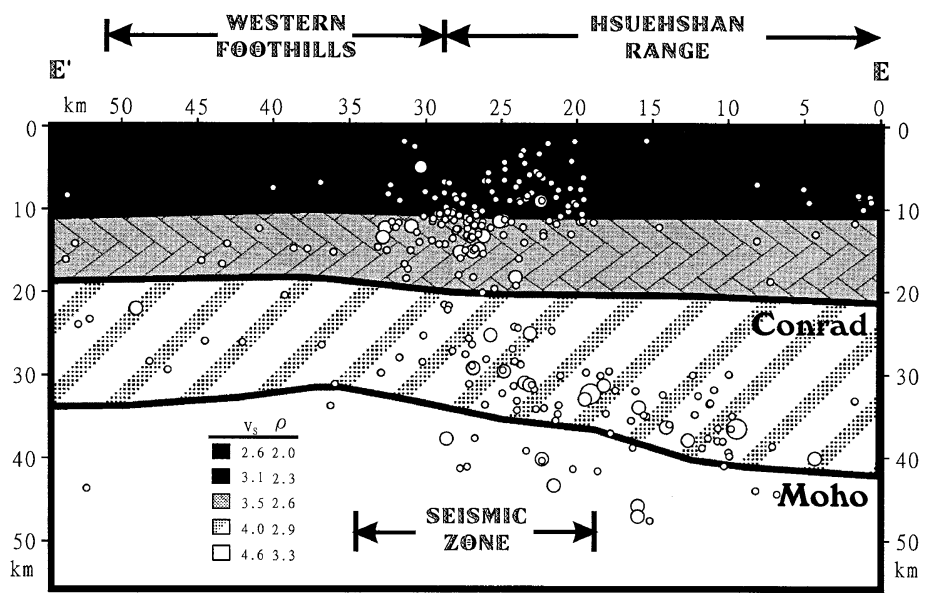

Fig. 2. Comparison of earthquake hypocentral locations and 2D $S$-wave velocity model along EE'. The Conrad discontinuity is at $\sim 20 \mathrm{~km}$, while the Moho becomes deeper toward the east. Both display variations across the Sanyi-Puli seismic zone. Vs ( $S$-wave velocity) in $\mathrm{km} / \mathrm{s}$ and $\rho$ (density) in $\mathrm{g} / \mathrm{cm}^{3}$. 
Range; moreover, the lower crust (the third layer) becomes thinner under the seismic zone than elsewhere. Earthquakes occurred in the Sanyi-Puli seismic zone can be grouped into two seismogenic layers. The upper seismogenic layer is at the depths of $5-15 \mathrm{~km}$ and the lower one is likely located within the lower crust and the uppermost mantle. It is worth to note that an aseismic zone is almost situated at the Conrad discontinuity.

\section{Magnetotelluric Data and Preliminary Resistiv- ity Structure}

Eight MT soundings across the Sanyi-Puli seismic zone were conducted during the last two years. A tensor MT survey, including 2 orthogonal electric field components and 3 magnetic field components, had been carried out in the field. The data were recorded by a real-time V5 MT-16 system (Phoenix Geophysics Ltd., Canada) with a capability of measuring the broad band EM signals ranging from 384 to $0.00055 \mathrm{~Hz}$. The data were generally collected over a time span of $\sim 12$ hours, up to 18 hours in the field. Data in the frequency range $384 \mathrm{~Hz}-9 \mathrm{~Hz}$ were processed in narrow frequency bands containing two frequencies (the 6 th and 8 th harmonics of the dataset length). Longer period data, $0.167 \mathrm{~s}-1820 \mathrm{~s}$, were processed using a cascade decimation scheme. The robust process had been used to reduce the variances of the off-diagonal MT impedance for some noisy sites.

Full interpretation of MT data will require a detailed analysis of possible distortions in the data (e.g. Groom and Bailey, 1989) and, at the very least, a two-dimensional modeling and inversion. However, certain inferences concerning the electrical structure, especially in the relatively near-surface, may be obtained from one-dimensional modeling and inversion. The apparent resistivities and phases (Fig. 3) used in this modeling are those calculated from the determinant impedance of Ranganayaki (1984). This parameter is invariant with rotation of the axial system and may be less sensitive to local three-dimensional structure (Ingham, 1988). It can be shown numerically that, in the case where the large-scale conductivity structure is one-dimensional, the determinant response in the presence of near-surface heterogeneities has a phase unaffected by the distortions and an apparent resistivity that is purely statically shifted (e.g. figure 2 of Ingham, 1988; figures 2 and 3 of Pellerin and Hohmann, 1990).

In our Sanyi-Puli MT dataset some soundings exhibit static splits at high frequencies (above $10 \mathrm{~Hz}$ ) between two apparent resistivity curves, while two phase curves overlay each other at the corresponding frequencies (Fig. 4). The severest one is site 84 with an anisotropy factor of $\sim 8$, as shown in Fig. 4, between two resistivity curves for high frequencies. Static effects in MT are caused by near-surface inhomogeneities. They manifest themselves as a vertical shift of the apparent resistivities by a frequency independent multiplicative factor without affecting the phases. Without a priori knowledge, it is difficult to estimate the correct level of MT resistivities. However, the determinant phase of observations is a true estimate of the determinant phase of the prevailing 3D bodies over 2D structures (Groom and Bailey, 1989). Thus, in more complex regions, it is also possible to gain useful electrical images for true structures by inverting
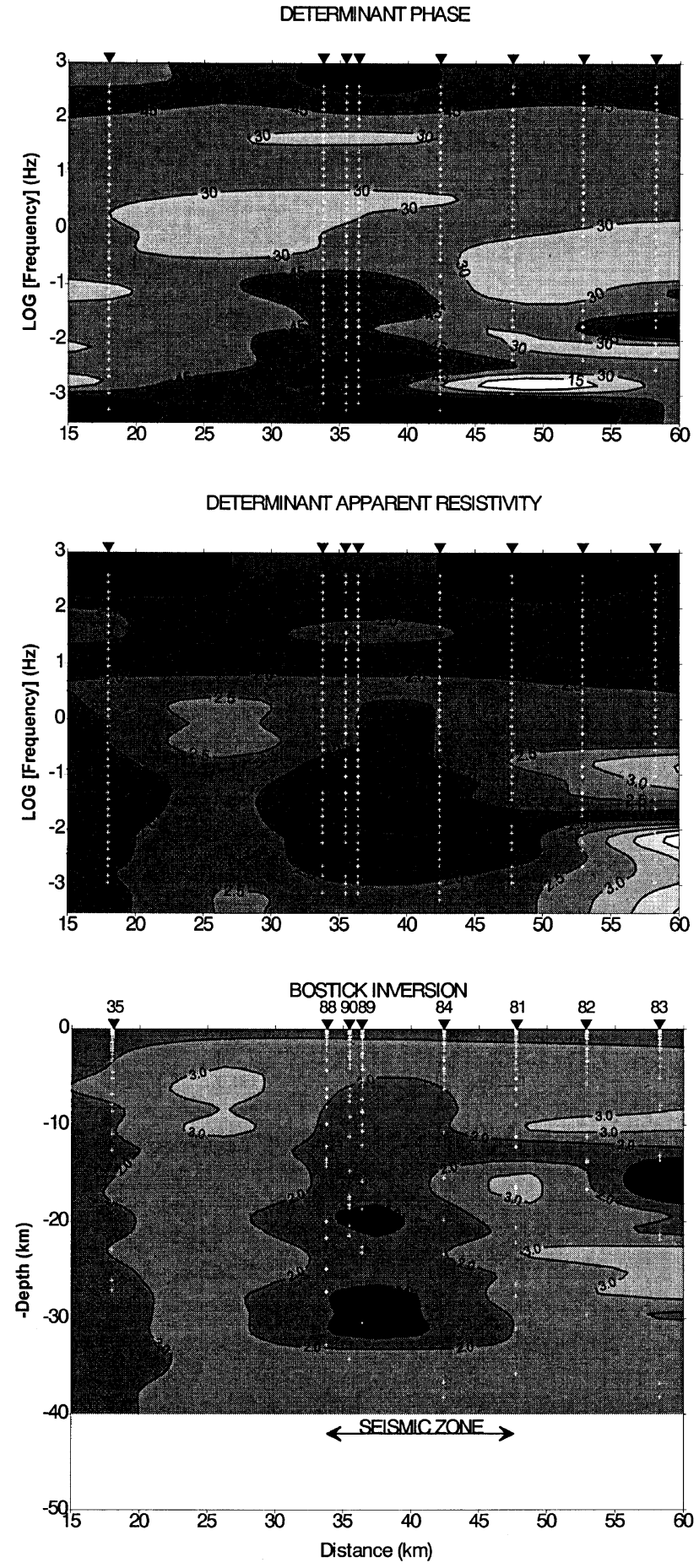

Fig. 3. Determinant phase (the unit of contour lines is in degree) and resistivity (in ohm-m) pseudosections and the Bostick depth section (in ohm-m) along the profile shown in Fig. 1. The darker colors depict the regions of lower-resistivity, whereas the brighter colors depict the higher resistivity. Existing a pronounced low resistivity zone beneath the Sanyi-Puli seismic zone. Crosses on each section are the frequency-sampling points and the depth-sampling points

the determinant average data (Oldenburg and Ellis, 1993).

To get a first overview of the MT results, pseudosections of both the determinant apparent resistivity and determinant phase are drawn across the Sanyi-Puli seismic zone (Fig. 3). For the almost 1-D behavior in the seismic model and the reason described above, we have shifted the determinant re- 


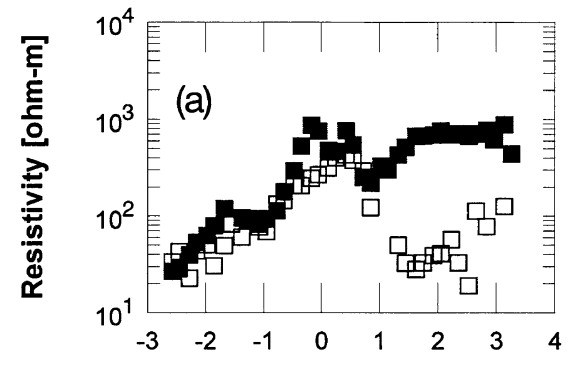

SITE 88

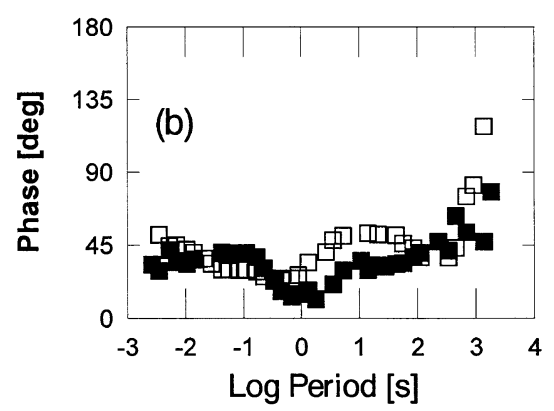

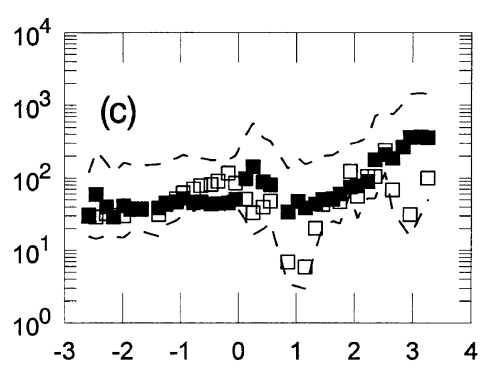

SITE 84

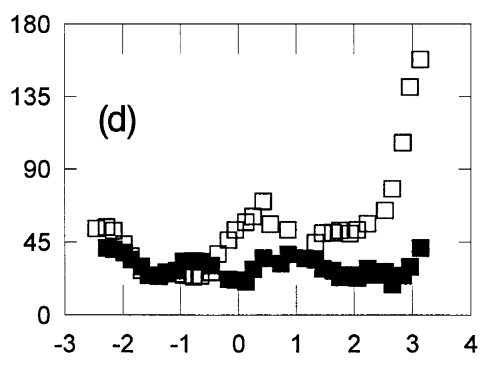

Fig. 4. Sounding curves of two sites 88 and 84 . Solid squares denote the TE mode responses and open squares the TM mode responses. The upper and lower dash lines in (c) represent unshifted/original TE and TM resistivity curves. While two phase curves in (d) overlay each other at high frequencies, a static splitting factor of $\sim 8$ for the two resistivity curves in (c) implies the static effect appears in site 84 . By multiplying the TE and TM resistivity curves by two factors of 0.25 (a downward shift) and 2 (an upward shift) can superpose two curves at high frequencies, and may reduce the static effect in site 84 . In the case of site 88 , no static shift is applied. For clarity uncertainties are not shown.

sistivity curves from some sites, multiplying these curves by frequency independent factors varying from site to site, to minimize the artificial features which are probably due to the static effect. Both $S$-wave velocity model and the high frequency phase data of two modes from all sites indicate the layered structure in the shallow depth. These multiplicative factors were thus chosen to keep the apparent resistivity data around $10 \mathrm{~Hz}$ similar for all sites. This multiplication is reasonable when assuming that a certain minority of soundings is clearly biased relative to the major responses in MT data (Dr. P. Wannamaker, pers. commun.). Although this assumption is not easy to confirm, because all modes of our MT soundings are possibly affected by varying amounts of static shift, an effective way to examine the results of this operation is to display the shifted apparent resistivity and phase pseudosections along a profile. As shown in Fig. 3, not only for the high frequencies but also for the long periods, these two pseudosections accommodate very well to each other after this shift.

MT phase is $45^{\circ}$ for a uniform layer. Phases greater than $45^{\circ}$ indicate a layer of lower resistivity than the layer above it, whereas phases less than $45^{\circ}$ indicate the converse. Beneath the Sanyi-Puli seismic zone, existing a region with the higher phases and the corresponding lower apparent resistivities around the frequency range $0.1 \sim 0.01 \mathrm{~Hz}$ suggests a pronounced feature concerned with the frequent seismic activities near the middle crust. To convert from frequency on the ordinate of the pseudosections to depth, we performed transformation by the Bostick inversion, according to the phases and the shifted apparent resistivities, to give a preliminary resistivity structure. This Bostick depth section is also illustrated in Fig. 3 and it confirms the marked anomaly in re- sistivity structure with the resistivity of $\sim 10$ ohm-meter and the depth of $\sim 20 \mathrm{~km}$ beneath the Sanyi-Puli seismic zone. It should be noted that the Bostick inversion gives a good qualitative result, but can be quantitatively poor. However, the $S$-wave velocity structure provides a constraint on this aspect. The lowest resistivity ( $<10$ ohm-meter) beneath the seismic zone are found around the Conrad discontinuity $(\sim 20 \mathrm{~km})$, being in agreement with the model proposed by Jones (1992) who compiled many electric structures from world wide MT data, particularly including the case of continental margins. This correlation give us confidence that our resistivity model is valid in its gross features.

\section{Causes of the Sanyi-Puli Seismic Zone}

The key geophysical constrains across the Sanyi-Puli seismic zone are: (1) A low-resistivity region of $\sim 10$ ohm-meter at the depths of $\sim 20 \mathrm{~km}$ beneath the Sanyi-Puli seismic zone. (2) A shallowing of the Moho discontinuity beneath this seismic zone. (3) An aseismic zone with a more ductile behavior in this area at the depths of $\sim 20 \mathrm{~km}$ corresponding to the Conrad discontinuity and the lowest resistivity zone.

Ague et al. (1998) proposed a possible link between metamorphic dehydration and earthquake nucleation. An overstepping temperature $(T)$ away from the equilibrium boundary of reaction results in the dehydration of hydrous minerals. $T$-overstepping results from many scenarios, say, rapid heating following emplacement of intrusions or $P f$ decrease following a fracturing and fluid release event. If the permeability of the rocks in the reaction zone is low and the described kinetic reaction overstepping happens initially for some unspecified reason, then $P f$ increases rapidly and exceeds the solid pressure. Consequently, hydrofracture and 
fault rupture follows, and released $P f$ induces another overstepping temperature. Such a mechanism may repeat and produce hundreds of episodes of elevated $P f$ and seismic events.

Ague's model prompts us to review the geological and geophysical data and to link them altogether. Amphibolite facies rocks in the Central Range, Taiwan, occur on conditions of $P=4 \sim 6 \mathrm{kbar}$ and $T=550 \sim 700^{\circ} \mathrm{C}$ at $\sim 20 \mathrm{~km}$ depth, and may be raised and crop out by imbrecated upthrusting caused by the collision of the Philippine Sea plate with the Eurasian continental plate (Chen and Wang, 1995). The dehydration reactions, in particular of serpentinite, may take place to supply the fluids. The thermal activation of ductility is strong enough to assist the rapid evolution of porosity and the rapid fluid transport below the brittle-ductile transition (Bailey, 1990), and consequently reduce the resistivity of the rocks around the depth of $20 \mathrm{~km}$ (Fig. 3). However, this mechanism vanishes above the brittle-ductile transition, resulting in the accumulation of fluids and the overpressure zone. Overpressured reservoirs existing below $\sim 5 \mathrm{~km}$ were reported by Suppe and Wittke (1977) in the Northwestern Taiwan, the bottoms of which remain suspect and unknown.

Only a small volume of fluid is necessary to trigger a seismic event in Ague's model, and there need be no observable change in seismic data. It is not the case, however, in MT investigations due to the high sensitivity of electromagnetic exploration for fluids in rocks (Jones, 1992). On the other hand, $T$-overstepping expected in Ague's model may be related to the shallowing of the Moho discontinuity beneath the Sanyi-Puli seismic zone as shown in Fig. 2, and accelerate the dehydration reactions.

\section{Discussion and Conclusion}

This letter reports a preliminary electrical structure across the Sanyi-Puli seismic zone. In future analysis of the MT data the distortions due to near-surface inhomogeneities should be taken further into account (e.g. Groom and Bailey, 1989). Subsequent 2-D modeling and inversion should then provide a much clearer indication of the Sanyi-Puli seismic zone conductivity anomaly. Rau et al. (1998) proposed a lithosphericscale model that is characterized by a transition from a thrust regime in the Central Range to an escape regime toward the Western Foothills in the foreland belt of central-western Taiwan. They suggested a localizing shear stress concentration provoked by the tectonic escape process in the region to explain the mechanism of the Sanyi-Puli seismic zone. While their model describes satisfactorily the mechanical behavior in the study area, MT data seems difficult to put strong constraints on the stress conditions in the deep crust. Despite these, our preliminary study, correlating the resistivity model with velocity structure and the active seismicity based on Ague's model, raises the possibility that metamorphic dehydration may itself be a partial cause of the Sanyi-Puli seismic zone. Some geological observations (e.g. Suppe and Wittke, 1977; Suppe, 1981), on the other hand, probably imply the existence of metamorphic dehydration in northwest Taiwan. In conclusion, for examining the important mechanisms to trigger the frequent seismic events in Sanyi-Puli area much more work including interdisciplinary studies is engaged.

Acknowledgments. This manuscript is greatly improved by Drs. Y. Ogawa and P. Wannamaker and one anonymous reviewer. The authors are indebted to them. We also thank Prof. K. F. Ma for useful suggestions on an early manuscript and Mr. S. J. Lee for plotting Figs. 1 and 2. This work was mainly supported by the National Science Council of R.O.C. under the grants NSC 89-2811-M-0010016 and NSC 88-2116-M-008-005.

\section{References}

Ague, J. J., J. Park, and D. M. Rye, Regional metamorphic dehydration and seismic hazard, Geophys. Res. Lett., 25, 4221-4224, 1998.

Bailey, R. C., Trapping of aqueous fluids in the deep crust, Geophys. Res. Lett., 17, 1129-1132, 1990 .

Chen, C. H. and C. H. Wang, Explanatory notes for the metamorphic facies map of Taiwan, Second Edition, 51 pp., Central Geological Survey, MOEA, Taipei, Taiwan, 1995 (in Chinese).

Deffontaines, B., J. C. Lee, J. Angelier, J. Carvalho, and J. P. Rudant, New geomorphic data on the active Taiwan orogen: A multisource approach, J. Geophys. Res., 99, 20,243-20,266, 1994.

Groom, R. W. and R. C. Bailey, Decomposition of magnetotelluric impedance tensor in the presence of local three-dimensional galvanic distortion, J. Geophys. Res., 94, 1913-1925, 1989.

Gudmundsson, A., Fluid overpressure and stress drop in fault zones, Geophys. Res. Lett., 26, 115-118, 1999.

Hsu, C. H., C. I. Lee, and J. F. Lee, NW-SE trending seismic zone in the Miaoli-Taichung-Nantou area, Central Taiwan, and its implication in tectonics, in Proceedings of The Sixth Symposium on Taiwan Quaternary, pp. 224-228, 1996 (in Chinese).

Ingham, M. R., The use of invariant impedances in magnetotelluric interpretation, Geophys. J. Int., 92, 165-169, 1988.

Jones, A. G., Electrical conductivity of the continental lower crust, in Continental Lower Crust, edited by D. M. Fountain, R. J. Arculus, and R. W. Kay, pp. 81-143, Elsevier, New York, 1992.

Lee, S. J., The $S$-wave velocity structure under central-western Taiwan by strong ground motion waveform modeling, M Sc. thesis, Nat. Central Univ., 138 pp., Chungli, Taiwan, 1999 (in Chinese).

Lin, C. H. and S. W. Roecker, Deep earthquakes beneath central Taiwan: mantle shearing in an arc-continent collision, Tectonics, 12, 745-755, 1993.

Oldenburg, D. W. and R. G. Ellis, Efficient inversion of magnetotelluric data in two dimensions, Phys. Earth Planet. Inter, 81, 177-200, 1993.

Pellerin, L. and G. W. Hohmann, Transient electromagnetic inversion: A remedy for magnetotelluric static shifts, Geophysics, 55, 1242-1250, 1990

Ranganayaki, R. P., The interpretive analysis of magnetotelluric data, Geophysics, 49, 1730-1748, 1984.

Rau, R. J., J. C. Lee, H. Kao, and H. T. Chu, Transition from convergence to escape: inferences from seismic tomography, seismicity, and focal mechanisms in the foreland belt of central-western Taiwan, J. Geophys. Res., 1998 (submitted).

Seno, T., S. Stein, and A. E. Gripp, A model for the motion of the Philippine Sea plate consistent with NUVEL-1 and geological data, J. Geophys Res., 98, 17,941-17,948, 1993.

Suppe, J., Mechanics of mountain building and metamorphism in Taiwan, Mem. Geol. Soc. China, 4, 67-89, 1981.

Suppe, J. and J. H. Wittke, Abnormal pore-fluid pressures in relation to stratigraphy and structure in the active fold-and-thrust belt of northwestern Taiwan, Petrol. Geol. Taiwan, 14, 11-24, 1977.

C.-C. Chen (e-mail: morse@earth.sinica.edu.tw) and C.-S. Chen 